\title{
Design of Moodle-based Podcast Teaching Platform for the Course of Aerobic Gymnastics
}

\author{
https://doi.org/10.3991/ijet.v12.i09.7490 \\ Yingbao Zhou \\ Nanjing Xiaozhuang University, Nanjing, China \\ zhouyb111@yeah. net
}

\begin{abstract}
A Moodle-based podcast teaching platform is designed for the course of aerobic gymnastics. Although abundant teaching tools and resources are available on the Moodle teaching platform, it doesn't support playing video and audio. Thus, podcast module is added. Podcast, as an innovative medium form, is convenient for playing video and audio. The key to learning aerobic gymnastics is to master the essentials of movements. We adopted the patented technology of a method and device of real-time animation generation in video in teaching, to help learners comprehend movements of aerobic gymnastics and raise learning efficiency. We also performed contrast experiment to check the effect of the teaching platform in teaching practice. The results show that the experimental group performed better than the control group in respect of both routine and movement, and demonstration capability. The platform is largely helpful for learners to comprehend the movements and raise learning efficiency. Thus, these findings indicate the Moodle-based podcast teaching platform has a good application prospect in physical education.
\end{abstract}

Keywords-Moodle, podcast, interaction, feedback

\section{$1 \quad$ Introduction}

With the rapid development of the internet technology, a new medium emergedpodcast. Podcast refers to a technology with which user can publish broadcast and download videos and audios freely. Podcast is mainly applied for recreation, information, marketing and profit making [1]. The application of podcast in teaching is mainly to use it as a medium of training course. Moodle, an acronym for modular object-oriented dynamic learning environment, is a network education platform provided with abundant teaching tools [2]. The combination of podcast with Moodle platform will have unique advantages and interaction functions, which is a creative learning mode.

The aerobic gymnastics courses in most universities appear to be dull, of incomplete teaching contents and objectives, and be with an irrational after-class evaluation system. Considering the aforesaid problems of the course of aerobic gymnastics, we have built a Moodle-based podcast teaching platform, and re-designed the course of aerobic gymnastics, with a purpose to arouse students' interest in aerobic gymnastics 
learning, improve the quality of teaching, promote student-student and student-teacher interactions, facilitate after-class evaluation, and raise learning efficiency.

\section{State of the art}

With the development of the Internet technology, distance education develops rapidly, so that university education is not limited to on-campus education any more, but also can be realized via online courses. The emergence of podcast marks the second reformation of the development of the Internet era. Created and developed in America, and brought into China around the early 2005 , podcast is a media form integrating voice and image. So far, podcast has had huge audiences. Concerning the application in distance education, podcast has four advantages, namely powerful interactional function, open sharing of resources, digital broadcasting form, and mobile learning mode. According to statistics, podcast is widely applied overseas, and more than 100 universities have applied podcast in teaching [3]. Obviously, podcast-based network courses are superior to ordinary classroom teaching, which are easy to operate via mobile terminal accessing to the internet. Podcast is an innovative medium. Its emergence has changed the correlation between the producer of distance teaching resources and the receivers. Thus, the producer of teaching resources is not limited to specific identity. Instead, anybody can create teaching resources. Applying podcast in teaching is helpful to promote communication between learners and teachers, and improve learners' cognitive competence [4].

Bongey et al. [5] applying podcasts to biology teaching, the results show that taken together, the responses to the main questions from the survey and the student selfreported comments strongly suggest that having podcast lectures available to students does not lead to large declines in class attendance. For the specific courses that were examined by this survey, students overwhelmingly preferred the actual lectures to the recorded podcasts. In addition, the large majority of students were using the podcasts to increase their understanding of material covered in specific lectures 。 Savel et al. [6] group (the Society of Critical Care Medicine) saw the educational and communication potential for the podcasting concept, and have successfully designed and implemented the first podcast of a national medical society. As of this writing, there are an average of (mean \pm SD) $664 \pm 290$ total downloads per podcast, and their podcast feed has been hit over 68,000 times in its first seven months. For the moment, podcast is not widely applied in China, and there are few relevant researches too. It is not brought to the forefront yet. There are only few scholars publishing analytical paper on it. Qian [7] studied the development of podcast platform for track and field curriculum, and Tang [8] studied the application of podcast in college physical education, and so on. With the rapid development of the Internet technology, the teaching of sports specialty also develops rapidly in China. But schools and teachers cannot keep pace with the development of the teaching of sports specialty. Schools fail to be provided with adequate facilities supporting distance education, teachers are not proficient enough, there is no rational pedagogical knowledge system and method to take the place of the traditional teaching mode and method [9-10]. In this research, a Moo- 
dle-based podcast teaching platform is designed for the course of aerobic gymnastics, with a view to changing the traditional teaching mode of aerobic gymnastics. Podcast is a good platform of communication and resource sharing for learners, with which learners can schedule their learning plan, and constantly improve themselves and raise learning efficiency by means of learning exchange with others [11].

The advantage of this research is that the podcast teaching platform is based on Moodle. Moodle is provided with abundant teaching tools. Thus, the combination of Moodle with podcast has unique superiority and can provide an advantageous communication platform. A method and device of real-time animation generation in video in teaching is added as teaching tool, with which the movements in videos can be captured in real time way to generate animations to help learners comprehend the essentials of movements of aerobic gymnastics. The Moodle-based podcast teaching platform designed for the course of aerobic gymnastics can help learners study course, download videos, and make communications and after-class evaluation. Abundant teaching resources are available on this platform. The real-time animation generation tool of video can help learners learn movements of aerobic gymnastics, which makes the learning process interesting.

\section{Model analysis}

\subsection{Moodle teaching platform}

Moodle is a universal network platform. It is mainly for improving teaching method, and suitable for development of online course. Both teacher and learners can act as the subject of the Moodle teaching platform. Learners can improve their learning via exchange and cooperation. Moodle system is of B/S three-layer architecture [12], as shown in Fig. 1, in which client, intermediate system and database stand independently. The intermediate system consists of user subsystem, teaching subsystem, communication subsystem, test subsystem, and administrator subsystem. User can log in the system via client to use the Moodle system. The interface is simple, which is easy to operate. The administrator can perform authorization and curricula construction via the administrator subsystem, and teacher user can perform teaching design, preparation, implementation, evaluation and feedback via the teaching subsystem. Student user can perform preview and course learning via the user subsystem, make communications on learning via the communication subsystem, and make evaluation via the test subsystem. Figure 1 is the $\mathrm{B} / \mathrm{S}$ three tier architecture diagram. Figure 2 is the general framework of the information construction theory.

Learners' academic record should be evaluated with the multivariate regression analysis method. A multivariate regression model is built according to the suppositional conditions, least squares estimator and the Gauss-Markov theorem, as below:

$$
y_{t}=\beta_{0}+\beta_{0} x_{t 1}+\beta_{1} x_{t 1} \mathrm{~K} \mathrm{~K}+\beta_{k-1} x_{t k-1}+u_{e}
$$


Wherein, yt is an explained variable (dependent variable), $\mathrm{xtj}$ is an explanatory variable, ut is a stochastic error term, and $\beta_{0}, 1,1, \ldots ., \mathrm{k}-1$ are regression parameters (usually unknown).

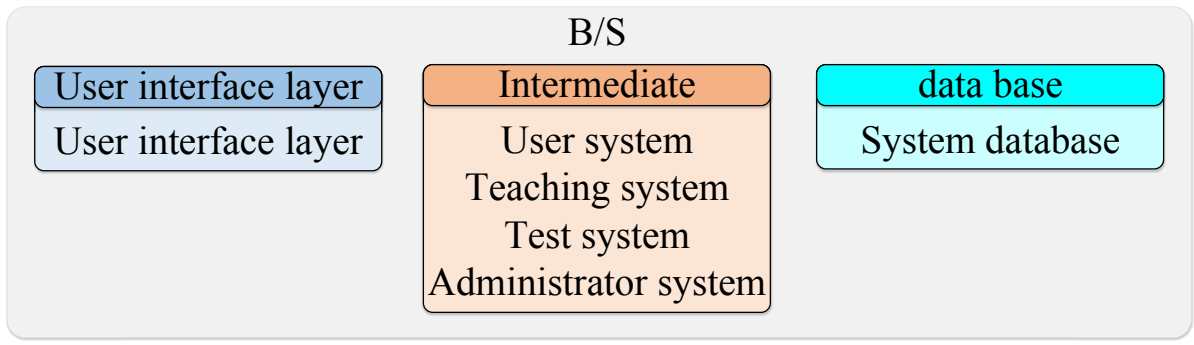

Fig. 1. B/S three-layer architecture

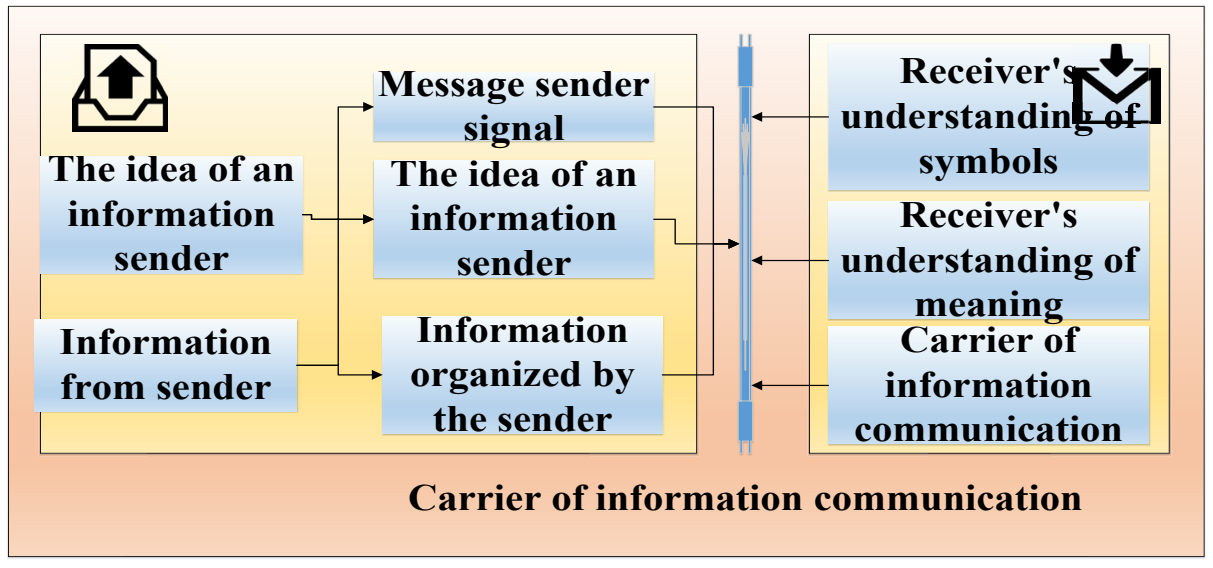

Fig. 2. The general framework of the information construction theory

\subsection{Addition of podcast media library}

Moodle teaching platform comes without a player, so that teacher cannot upload audio or video to the teaching platform. This problem can be solved by adding podcast plug-in into the Moodle teaching platform. Except for addition of regular teaching courses, audios and videos should be added separately via the podcast module. Besides, we introduced the technology of animation generation with real-time captured movements from videos into the podcast module, which can help learners comprehend the movements and arouse learners' interest.

\subsection{Application of the information architecture theory}

The content design and interface design of the teaching platform were carried out based on the information theory. The information theory is a system for evaluating 
website, based on which we can improve website design via the composite indicators. The aforesaid evaluation parameters include navigation design, classificaiton system design, interaction design, search design and sign design. Navigation design aims to facilitate user operation; classification system design mainly refers to presenting teaching contents by classification and showing the link among the teaching contents in the page; interaction design is an important link, which provides multiple interactive modes to facilitate users' communication; sign design aims to make keywords of knowledge unique.

\section{Design of Moodle-based podcast teaching platform}

\subsection{Curriculum design of aerobic gymnastics for the Moodle-based podcast teaching platform}

The structure of Moodle system is as shown in Fig. 3.The operation interface of Moodle is simple and easy to operate. The design architecture of the Moodle-based podcast teaching platform is as shown in Fig. 4. User can add podcast media library module to the self-contained teaching tools of Moodle to enable playing of videos and audios. Besides, user can download videos and audios from the platform easily. The content design of curriculum is undertaken by teacher, and learners study courses via the platform. This platform is helpful to arouse learners' interest and improve learning efficiency.

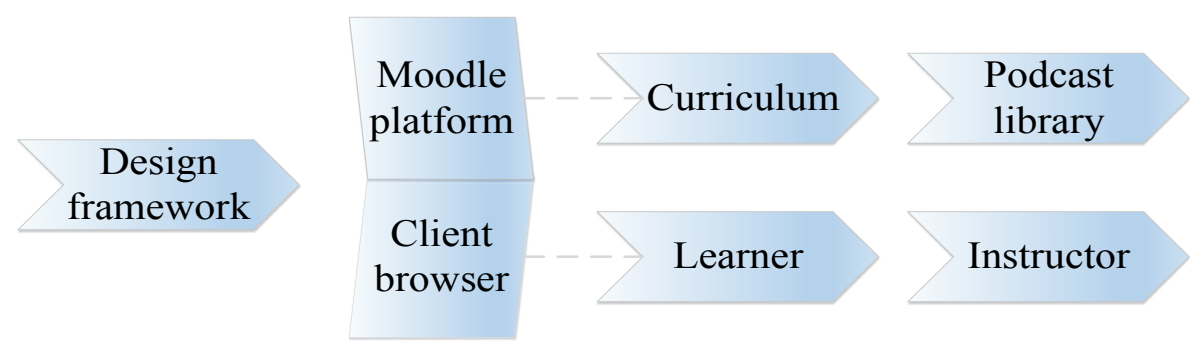

Fig. 3. Design of Moodle-based podcast teaching platform

As shown in fig.3, teacher is responsible for teaching design, teaching preparation, implementation of teaching, and teaching evaluation. Teacher can upload network courses in the form of audio or video to the teaching platform after having determined the teaching objectives, teaching plan and evaluation indexes. After preview, students will be led by teacher to enter the platform for course learning, online discussions via the interaction function, and learning evaluation after finishing homework. Teacher should abide by the following principles while setting curriculum design objectives:

Interactive principle. Teacher should adhere to the principle of information theory in teaching content design to realize interactivity and feedback, as shown in Fig. 4. Thus, teacher can guide learners in preview stage, to help arouse learners' learning desire; then guide learners to use the Moodle-based podcast teaching platform for 
course learning. It is extremely important for learners to grasp the movement skills in the learning of the course of aerobic gymnastics, which is dull for learners, however. Thus, teacher needs to take measures to arouse learners' initiative in teaching content design. Specifically, teacher can help learners to do learning by imitation by showing action videos, and explore the essentials of movements by means of communication and discussion.

The principle of feedback. Teacher should perform teaching evaluation via assignment and test, and focus on learners' self-assessment and communication for evaluation. Thus, teacher can constantly adjust the teaching contents based on the feedbacks.

Besides, teacher also can make full use of the functions of the teaching platform. Teacher can learn about learners' learning condition via the learning record tracking module of the teaching platform, and make a learning report based on the data of the record.

Learners also are the subject of the Moodle-based podcast teaching platform in the teaching of aerobic gymnastics. Before learning, learners can browse the course introduction, course outline, and curriculum plan to have a rough idea of the course, read and learn learning materials and watch videos before formal course learning, and make discussions online and communicate with other learners via the communication module.

The teaching contents, teaching plan and teaching objectives of the course of aerobic gymnastics will be designed by teacher. To tackle this task, teacher should stand in learners' shoes to put up questions, so as to raise learners' enthusiasm and avoid dullness of traditional teaching method. Course title and course description are available on the main modules of the course, via which user can have an access to a detailed learning interface. The podcast media library module is presented on the course content module separately, via which teacher can add videos and audios, and learners can watch and download videos and audios. Figure 4 is an interactive teaching design of information theory based on Moodle podcast teaching platform

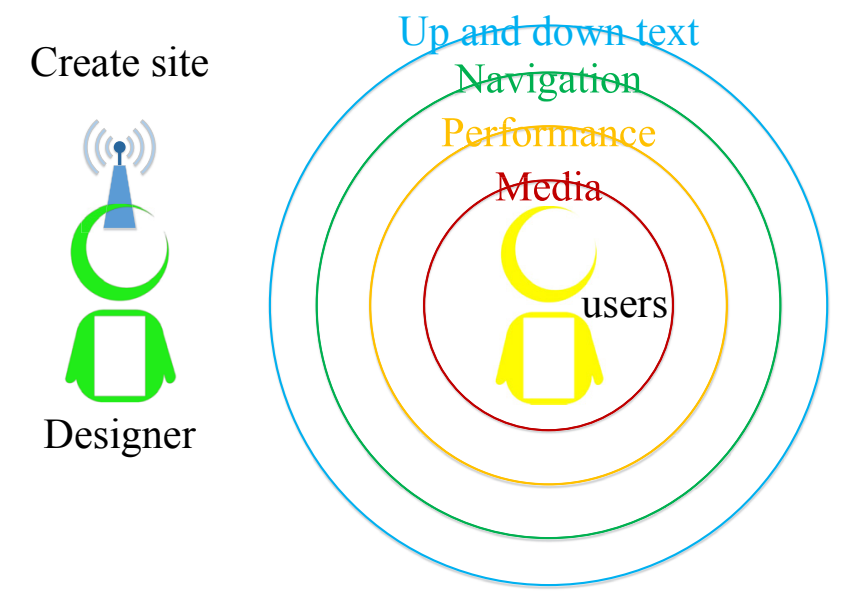

Fig. 4. Interactive content design based on information theory 


\subsection{Interface presentation of Moodle-based podcast teaching platform applied in the teaching of aerobics gymnastics}

The login interface of the Moodle-based podcast teaching platform applied in the teaching of aerobics gymnastics is as shown in Fig. 5. User should acquire authorization from the administrator first, and then log in with user ID and password via this interface. Users can have an access to different contents granted within their rights. Teacher is mainly responsible for design of teaching contents and upload of materials, and learners are main users of the platform. Figure 6 is a screenshot of the Moodle based podcast teaching platform. This interface will appear once learners log in. It mainly consists of four parts, namely introduction before class, course learning, communication platform and after-class evaluation. The part of introduction before class is for arousing learners' interest. The part of course learning is provided with podcast module. The movements of aerobic gymnastics are mainly learned via video. With the podcast module, user can generate animations about the contents not easy to understand with certain tools to help learners. Learners can communicate with teacher and other learners via the communication platform, to promote their learning. The part of after-class evaluation is for evaluating learners' learning condition via test, to help learners understand their weakness, and teacher learn about learners' learning condition.

\subsection{Experiment design and data analysis}

To check the effectiveness of this teaching platform, we conducted an experiment on the course of aerobic gymnastics with 100 students of Grade 2016 of the depart-

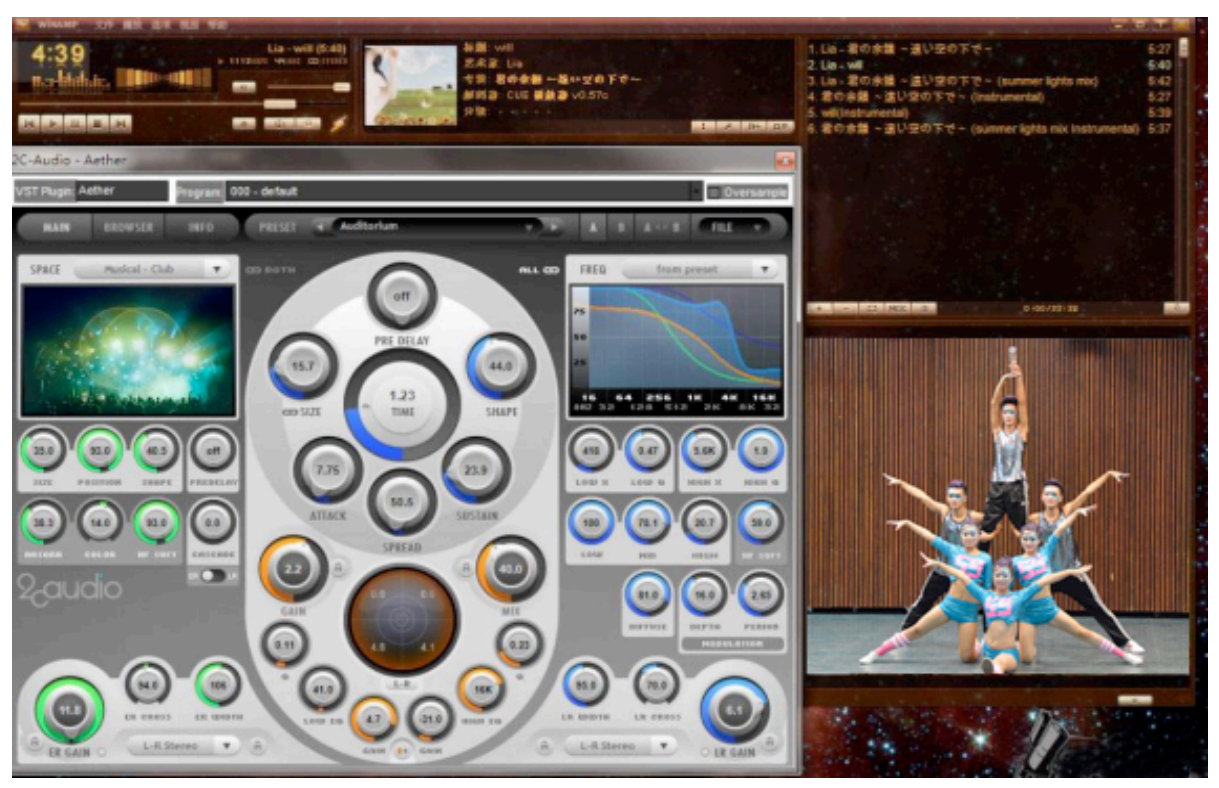

Fig. 5. Mac GarageBand 3 podcast recording software interface 
ment of physical education of a university. The 100 students were divided into two groups, a control group for which traditional teaching method was adopted, and an experimental group for which the Moodle-based podcast teaching platform was applied. The experimental period is one semester. An analysis was made on the performance of routine and movement and demonstration capability of the two groups, and the results are as shown in Tab. 1 and Tab. 2.

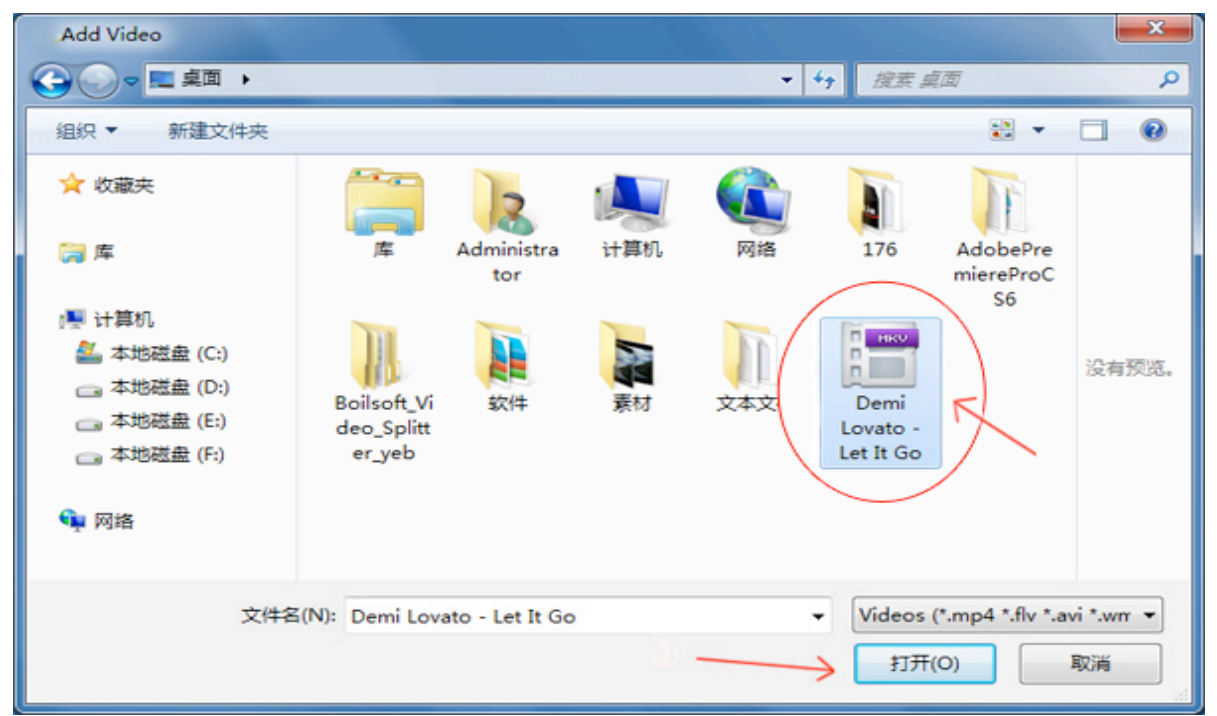

Fig. 6. Moodle based podcast teaching platform production screenshot

Table 1. Analysis on the performance of routine and movement of the two groups

\begin{tabular}{|l|c|c|c|c|c|}
\hline \multicolumn{1}{|c|}{ Group } & Excellent & Good & Average & Pass & Fail \\
\hline Experimental group & 7 & 28 & 11 & 4 & 0 \\
\hline Percent & $15 \%$ & $55 \%$ & $22.5 \%$ & $7.5 \%$ & $0 \%$ \\
\hline Control group & 4 & 27 & 22 & 7 & 0 \\
\hline Percent & $7.5 \%$ & $32.5 \%$ & $45 \%$ & $15 \%$ & $0 \%$ \\
\hline
\end{tabular}

Table 2. Analysis on the demonstration capability of the two groups

\begin{tabular}{|l|c|c|c|c|c|}
\hline \multicolumn{1}{|c|}{ Group } & Excellent & Good & Average & Pass & Fail \\
\hline Experimental group & 7 & 34 & 8 & 1 & 0 \\
\hline Percent & $15 \%$ & $67.5 \%$ & $15 \%$ & $2.5 \%$ & $0 \%$ \\
\hline Control group & 5 & 21 & 19 & 5 & 0 \\
\hline Percent & $10 \%$ & $42.5 \%$ & $37.5 \%$ & $10 \%$ & $0 \%$ \\
\hline
\end{tabular}

For the learning of aerobics gymnastics, routine and movement and demonstration capability are the two basic evaluation criteria. According to Tab. 1, the experimental group performed better than the control group in respect of routine and movement. According to Tab. 2, the experimental group also performed better than the control 
group in respect of demonstration capability. It is thus clear that the Moodle-based podcast teaching platform is helpful to improve students' learning efficiency.

Besides, we also conducted a questionnaire survey over the 100 students, and the result is as shown in Fig. 7. 47 students of the experimental group showed like with the teaching platform, 20 students showed very like; 40 students of the control group showed like with the teaching platform, and 27 students showed very like. Thus, we can see the new-type distance education platform is attractive to students. Usually, students favor learning in an interesting way, and want to allocate time freely.

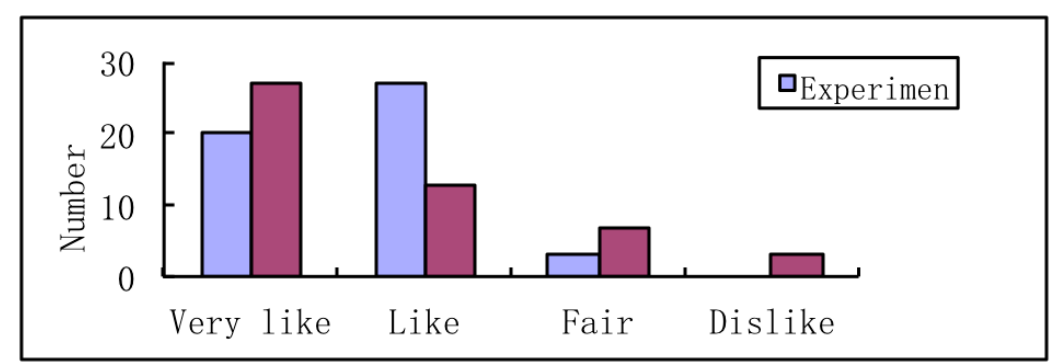

Fig. 7. Comparison of questionnaire survey results between the experimental group and the control group

The results as shown above suggest that the Moodle-based podcast teaching platform is relatively attractive to learners, the students of the experimental group had achieved remarkable result, learners can download and watch videos via the podcast module and generate animations of motion simulation with tools to help comprehend and grasp movements, and learners' learning interest and efficiency also had been improved.

\section{Conclusions}

The traditional teaching methods have become inadequate to meet the learning needs of learners of physical education curriculum, and distance education is expected to the main education mode in future. Podcast, an innovative medium form in the Internet era, has a broad application prospect in the field of education. In this paper, a Moodle-based podcast teaching platform is designed for the course of aerobic gymnastics, and it is proved that podcast is helpful to arouse learners' learning interest and convenient for learners to do study by means of teaching effect check. The Moodle platform provides abundant teaching tools. Besides, we have added the technology of real-time animation generation based on movements captured from videos, which makes the learning process of aerobic gymnastics interesting, and enables learners to communicate with teacher and other learners via the interaction module, to improve learning efficiency. However, this paper is just a design research about the application of Moodle-based podcast teaching platform in the teaching of aerobic gymnastics. In China, podcast hasn't attracted enough attention in the field of education, so it is a long way before podcast is widely applied in education. 


\section{References}

[1] Schreiber, B.E., Fukuta, J., Gordon, F. Live lecture versus video podcast in undergraduate medical education: A randomised controlled trial. Bmc Medical Education, 2010, vol. 10(1), pp. 68. https://doi.org/10.1186/1472-6920-10-68

[2] Merhi, M.I. Factors influencing higher education students to adopt podcast: Anempirical study. Computers \& Education, 2015, vol. 83, pp. 32-43. https://doi.org/10.1016/j.comp edu.2014.12.014

[3] Evans, C. The effectiveness of m-learning in the form of podcast revision lectures in higher education. Computers \& Education, 2008, vol. 50(2), pp. 491-498. https://doi.org/10.1016/j.compedu.2007.09.016

[4] Williams, A.E., Aguilar-Roca, N.M., O’Dowd, D.K. Lecture capture podcasts: differential student use and performance in a large introductory course. Educational Technology Research and Development, 2016, vol. 64(1), pp. 1-12. https://doi.org/10.1007/s11423-0159406-5

[5] Bongey, S.B., Cizadlo, G., Kalnbach, L. Explorations in course-casting: podcasts in higher education. Campus-Wide Information Systems, 2006, vol. 23(23), pp. 350-367. https://doi.org/10.1108/10650740610714107

[6] Savel, R.H., Goldstein, E.B., Perencevich, E.N., et al. The iCritical Care Podcast: A Novel Medium for Critical Care Communication and Education. Journal of the American Medical Informatics Association Jamia, 2007, vol. 14(1), pp. 94-99. https://doi.org/10.1197/ jamia.M2205

[7] Qian, L.P., Wang, Q. The application of podcasting in teaching based on campus network. Success (Education), 2010, vol. 4(9), pp. 191-191.

[8] Tang, L.J., Tang, B., Ji, L. An experimental study of podcasting in college students' Physical Education. Journal of Sports Adult Education. 2011, vol. 18(2), pp. 81-82

[9] Zualkernan, I.A., Husseini, G.A., Loughlin, K.F., et al. Remote Labs and Game-Based Learning for Process Control. Chemical Engineering Education, 2013, vol. 47(3), pp. 179188.

[10] Li, D.X. Information architecture for supply chain quality management. International Journal of Production Research, 2011, vol. 49(1), pp. 183-198. https://doi.org/10.1080/00207543.2010.508944

[11] Escobar-Rodriguez, T., Monge-Lozano, P. The acceptance of Moodle technology by business administration students. Computers \& Education, 2012, vol. 58(4), pp. 1085-1093. https://doi.org/10.1016/j.compedu.2011.11.012

[12] Romero, C., Ventura, S., García, E. Data mining in course management systems: Moodle case study and tutorial. Computers \& Education, 2008, vol. 51(1), pp. 368-384. https://doi.org/10.1016/j.compedu.2007.05.016

\section{$7 \quad$ Author}

Yingbao Zhou is a Lecturer of School of Department of Physical Education, Nanjing Xiaozhuang University, Nanjing 210028, China. His research interests include Physical Education and Sports Exercise. (zhouyb111@yeah.net).

Article submitted 02 April 2017. Published as resubmitted by the author 19 July 2017. 